\title{
High insect pest damage increases faba bean (Vicia faba) yield components but only in the absence of insect pollination
}

\author{
Laura Riggi ${ }^{1}$, Chloé Raderschall ${ }^{1}$, and Ola Lundin ${ }^{1}$ \\ ${ }^{1}$ Swedish University of Agricultural Sciences
}

September 24, 2021

\begin{abstract}
Identifying and quantifying crop stressors interactions in agroecosystems is necessary to guide sustainable crop management strategies. Over the last 50 years, faba bean cropping area has been declining, partly due to yield instabilities associated to uneven insect pollination and herbivory. Yet, interactions between pollinators and a key pest, Bruchus rufimanus (florivorous and seed predating herbivore), on faba bean yield have not been investigated. Using a factorial cage experiment in the field we investigated how interactions between two potential stressors, lack of pollination from Bombus terrestris and herbivory by $B$. rufimanus, affect faba bean yield. Lack of insect pollination reduced bean weight per plant by $15 \%$. Effects of $B$. rufimanus herbivory differed between the individual plant and the plant-stand scale (i.e. when averaging individual plant scale responses), likely due to high variation in the level of herbivory among individual plants. At the individual plant scale, B. rufimanus herbivory increased yield but only in the absence of pollinators, possibly due to plant over-compensation and/or pollination by B. rufimanus. At the plant-stand scale, we found no effect of B. rufimanus on yield. However, there was a tendency for heavier individual bean weight with insect pollination, but only when B. rufimanus herbivory was absent, possibly due to a negative effect of $B$. rufimanus on the proportion of legitimate flower visits by $B$. terrestris. This is the first experimental evidence of interactive effects of $B$. terrestris and B. rufimanus on faba bean yield. Our preliminary findings of negative and indirect associations between $B$. rufimanus and individual bean weight call for a better acknowledgment of these interactions in the field in order to understand drivers of crop yield variability in faba bean. This study showed that herbivory can increase yield, but this effect is only detectable when investigated in combination with lack of pollination.
\end{abstract}

\section{Introduction}

Stressors are biotic or abiotic variables that cause a negative response in a taxa or community (Barrett et al., 1976; Vinebrooke et al., 2004). For crop plants that benefit from insect pollination, insect herbivory and a lack of pollination can be referred to as biotic stressors if they negatively affect yield. Occasionally, compensatory responses may result in higher yields in herbivore-attacked plants compared to un-attacked plants (overcompensation, Poveda et al., 2010) and pollination benefits to yield may vary from negative to positive within and between cultivars (Bishop et al., 2020; Lundin \& Raderschall, 2021). Therefore, the characterization of herbivory and lack of pollination as crop stressors is not clear cut, but rather a nuanced one that will depend on the frequency, timing and quantity of herbivory/pollination as well as modifiers such as nutrient availability and cultivar (Poveda et al., 2010). To characterize crop stressors it is thus important to explore such nuances (e.g. does herbivory or lack of pollination lead to yield overcompensation?) and investigate the potential for interactions among hypothesized stressors on crop yield (Peterson \& Higley, 2000; Piggott et al., 2015). Stressors can interact in an additive, synergistic or antagonistic manner on plant growth and reproduction, making net effects on crop yield challenging to predict (Supplementary material, Fig. S1A). Empirically quantifying plant stressors and their interactions, particularly in agroecosystems, will help guide sustainable crop management strategies (Cote et al., 2016; Gagic et al., 2019; Saunders et al., 2016; Sutter \& Albrecht, 2016). 
Lack of insect pollination and insect herbivory may independently (additively), synergistically or antagonistically affect yield of pollinator-dependent crops. A synergistic effect between these stressors would result when the combined negative effect on yield, due to low insect pollination and herbivory, is higher than the sum of their individual effects. Alternatively, an antagonistic effect would result when yield loss due to lack of insect pollination and herbivory is lower than the sum of their individual effects. This may be the case if herbivore-induced plant overcompensation has the capacity to minimize the negative effect of lack of pollination (Järemo et al., 1999; Munguía-Rosas et al., 2015) or if the herbivore directly benefits plant reproduction by acting as a pollinator (i.e. some florivores, see: McCall \& Irwin, 2006). Interactions between insect pollination and herbivory have recently been found to influence plant trait evolution (Ramos \& Schiestl, 2019) and crop yield (Bartomeus et al., 2015; Gagic et al., 2019; Garibaldi et al., 2018; Lundin et al., 2013; Raderschall et al., 2021; Saunders et al., 2016; Sutter \& Albrecht, 2016; Tamburini et al., 2019). Compensatory responses of crops to herbivory, and effects of florivorous herbivores on yield are important and under-investigated mechanisms as they can maintain or even increase yield of crops exposed to pests (Gagic et al., 2016; Poveda et al., 2018). A recent meta-analysis found that overcompensation for insect herbivory in plants is pervasive and can increase crop yield (Garcia \& Eubanks, 2019). For example, flower abortion due to herbivory can lead damaged plants to grow larger fruits (Sanchez \& Lacasa, 2008) or produce more flowers (Peschiutta et al., 2020) than plants without herbivory. Despite yield increases, overcompensation due to herbivory may decrease yield quality (Peschiutta et al., 2020) and reduce the marketable crop. These mechanisms in interaction with pollination services can be particularly important in crops with large compensatory potential to biotic and abiotic stressors, such as faba bean (Vicia faba L.) (Lopez-Bellido et al., 2005).

Faba bean is an important nitrogen-fixating legume crop grown worldwide (Jensen et al., 2010; Karkanis et al., 2018). Over the past 50 years, faba bean cropping area has been declining due to yield instabilities, associated to abiotic stress, pest and pathogen pressure (Karkanis et al., 2018), and possibly uneven insect pollination. Faba beans are partially dependent on insect pollinators (Bishop \& Nakagawa, 2021). While insect pollination generally increases faba bean yield and yield stability (Suso \& del Rio, 2015; Suso \& Maalouf, 2010), pollination dependence within cultivars varies greatly, from -4 to $46 \%$ (loss in yield per plant without pollination)(Bishop et al., 2020). A recent study found that insect pollination benefit in faba bean, measured as the increase in bean weight per plant, lessened with aphid herbivory (Raderschall et al., 2021). This variability in pollination benefit underlines the importance to investigate interactions between pollinators and major pests if we want to understand factors affecting yield variability in faba beans.

A key pest in faba bean is Bruchus rufimanus (Boh.) (Segers et al., 2021). Adult beetles colonise the crop in spring to feed on pollen and nectar, and start laying eggs on developing pods (Segers et al., 2021). When the larvae hatch, they bore through the pods and develop and feed inside the beans. We use the term 'herbivory' to include both florivory by the B. rufimanus adults and seed predation by the larvae. Larval feeding reduces seed weight and quality (Epperlein, 1992; Roubinet, 2016; Segers et al., 2021). Adult beetles might have additional negative effects on yield if their feeding on pollen disrupts pollinator visitation (Ye et al., 2017), or, alternatively, positive effects if they pollinate (Krupnick \& Weis, 1999; McCall \& Irwin, 2006). Interactions between pollinators and B. rufimanus on faba bean growth and yield have so far not been investigated.

Here we evaluate the effect of herbivory by the pest $B$. rufimanuson faba bean yield components and ask how interactions between two hypothesized stressors, namely lack of pollination from bumblebees, and herbivory by $B$. rufimanus, affect above- and belowground plant traits and yield of faba bean. Specifically, we investigate whether flower visitation by pollinators changes with the inclusion of herbivores, and/or if there is over-compensatory growth of the plant in response to B. rufimanus damage in the presence of pollinators.

\section{Material and Methods}

Field experiment set-up

To assess the individual and interactive effects of the two stressors herbivory and lack of pollination on faba 
bean, we conducted a cage experiment in 2020 in a faba bean field in Uppsala, Sweden (59deg50'29.12'N; $17 \mathrm{deg} 42^{\prime} 02.44$ 'E). We conducted a fully-crossed two-factor field experiment, with presence and absence of herbivores $(\mathrm{H}+/ \mathrm{H}-)$ and pollinators $(\mathrm{P}+/ \mathrm{P}-)$, where $\mathrm{H}+$ and $\mathrm{P}$ - were the stressed level of each factor. Each $\mathrm{H}$ and $\mathrm{P}$ treatment combination had seven replicates $(\mathrm{N}=28$ in total), arranged in seven blocks, with one treatment combination per block (Fig. S2). We used $2 \times 2 \times 2 \mathrm{~m}$ cages covered with a nylon net (mesh size: $0.6 \times 0.6 \mathrm{~mm}$ ) to control the access of the herbivores and pollinators to the crop. Faba beans seeds (cultivar: Tiffany, Scandinavian Seed) were planted in the field on the $24^{\text {th }}$ of April (plant density per $\mathrm{m}^{2}$ : mean + -sd $=58.4+-8.5)$, and plants were treated with the fungicide Signum $\left(0.5 \mathrm{~kg} \cdot \mathrm{ha}^{-1}\right.$, BASF; $267 \mathrm{~g}^{\mathrm{kg}} \mathrm{kg}^{-1} \mathrm{boscalid}$ +67 g. $\mathrm{kg}^{-1}$ pyraclostrobin) on the $15^{\text {th }}$ of June, before flowering (BBCH-51) and prior to bumblebee hive inclusion, to avoid negative impacts on pollinators (Fisher et al., 2021).

\section{Herbivore inoculation}

B. rufimanus were collected over two weeks in early June from faba bean crops in the southern region of Vastergotland, where they had already colonised the earlier flowering fields. In the $\mathrm{H}+$ treatment cages $(\mathrm{N}=14), 45$ B. rufimanus individuals per $\mathrm{m}^{2}$ (0.77 individuals per plant) were inoculated on the $16^{\text {th }}$ of June, before crop bloom (BBCH-51:59). This pest density was chosen based on surveys of B. rufimanusconducted by the Swedish Board of Agriculture in 55 faba bean fields across Sweden between 2016-2019, which found that maximum naturally occurring pest incidences in commercial faba bean fields were $0.5-1 B$. rufimanus per plant, depending on the region. To control for herbivores in the $\mathrm{H}$ - treatment $(\mathrm{N}=14)$, cages were checked for B. rufimanus and any individual was removed prior to pollinator supplementation. No other faba bean crop pests, such as aphids, were detected in the cages.

Pollinator supplementation and flower visitation

To create a $\mathrm{P}+/ \mathrm{P}$ - treatment we supplemented $\mathrm{P}+$ cages $(\mathrm{N}=14)$ with bumblebee hives (Bombus terrestris L. , Natupol Seed, Koppert, https://www.koppert.com/natupol-seeds/) on the $22^{\text {nd }}$ of June at the onset of flowering (BBCH-61). The hives contained approximately 2-5 workers foraging for pollen and nectar and 5-8 males collecting nectar. Hives were placed at $1 \mathrm{~m}$ above the ground facing east for the duration of crop flowering, until the $27^{\text {th }}$ of July. At the end of the experiment, we found high variation in the abundance of bumblebees inside each hive (mean + -sd $=13.6+-5.1$ ), but there were no differences in bumblebee abundances between $\mathrm{H}+/ \mathrm{H}$ - treatments ( $\mathrm{t}$-test: $\mathrm{p}=0.4$ ) and bumblebee abundances in the hives was not correlated with pollinator visitation rates (Pearson rho: -0.14 ).

To investigate effects of herbivores on pollinators we carried out pollinator visitation observations in each $\mathrm{P}+$ cage in both herbivory treatments $(\mathrm{N}=14)$. Between the $23^{\text {rd }}$ of June and the $10^{\text {th }}$ of July, pollinators in $\mathrm{P}+$ cages were surveyed 15 times. Surveys were carried out under good weather conditions $(>15 \operatorname{deg} \mathrm{C}$ and no rain) between 1-6 pm. After each survey, the number of open flowers were counted, initially on 10 plants and from the $7^{\text {th }}$ of July, when flowering was decreasing (survey round 7), in a $1 \mathrm{~m}^{2}$ quadrat $(\mathbf{1} / \mathbf{4}$ of the cage). The same plants and quadrat were observed in every survey round. Pollinator visitation rate per flower and foraging behaviour were recorded for a duration of $10 \mathrm{~min}$, initially on the 10 plants, where the number of flowers had been counted and later in the $1 \mathrm{~m}^{2}$ quadrat. For each visit, we noted whether pollinators were legitimately visiting flowers by inserting their proboscis through the front of the flower opening, visiting extra floral nectaries (EFN) located underneath the stipules, or robbing nectar by inserting their proboscis through a hole at the base of the flower tube (Tasei, 1976). Because of low nectar reserves in all the hives due to spillage during transportation, pollinator behaviour might have been affected in the first half of the experiment, with more nectar robbing behaviour than would have been the case if hives had not been sugar-starved. From the $7^{\text {th }}$ of July, each colony was supplemented with sugar-water. The timing of sugar-water supplementation was included as a factor in the analyses of pollinator visitation and foraging behaviour.

\section{Plant measurements}

We estimated plant density by counting the number of plants within a $0.25 \mathrm{~m}^{2}$ quadrat randomly placed in each cage. When pods reached maturity (BBCH-89), on $10^{\text {th }}$ of September, 20 plants (stem, leaves, pods 
and roots) were collected per cage. On each plant, we counted the number of pods, number of beans per pod, proportion of damaged beans (beans with B. rufimanus emergence holes), plant height and tap-root length. Pods were classified into three categories: mature, immature (small and green) and unfertilized (without beans inside). Roots were washed with water. Aboveground plant (stems and leaves) and root biomass and bean weight for each plant were dried at $65 \mathrm{deg} C$ for 48 hours and subsequently weighed. Beans per pod was averaged per plant prior to statistical analyses, beans per plant was calculated by summing the number of beans across pods per plant and individual bean weight was calculated by dividing bean weight per plant with number of beans per plant. Yield in $\mathrm{kg}_{\mathrm{h}} \mathrm{ha}^{-1}$ was calculated for each cage by multiplying average bean weight per plant with plant density.

\section{Data analyses}

We used generalised linear mixed-effects models to test the interactive effects of herbivory and pollination treatments on: (a) proportion damaged beans per plant (beans with B. rufimanus emergence holes) (b) faba bean yield components (individual bean weight, total bean weight per plant, number of beans per pod, number of beans per plant, number of pods (mature, immature and unfertilized) per plant, proportion of mature pods per plant, and yield $\left(\mathrm{kg} \cdot \mathrm{ha}^{-1}\right)$, and (c) plant growth components (plant height and aboveground biomass, root length and biomass). Normal distributions were used except for number of pods and beans per plant, where a Poisson distribution was used or a negative binomial when data was overdispersed, and for proportion of damaged beans and mature pods per plant where a binomial distribution was used (see Table 1 for model structures). The explanatory variables in all models included the $\mathrm{H}+/ \mathrm{H}$ - and $\mathrm{P}+/ \mathrm{P}$ - treatments and their interaction term. Despite the care taken to remove B. rufimanusfrom the $\mathrm{H}$ - cages at the beginning of the experiment, beans with emergence holes were also found in these cages, and there was a large variation in damage between plants within each $\mathrm{H}+/ \mathrm{H}$ - cage (Fig. S3). We therefore, in addition to the main $\mathrm{H}+/ \mathrm{H}-$ treatment effect (i.e. plant-stand scale, measured by averaging individual plant scale responses in each cage), investigated the effect of herbivory damage at the plant scale, measured as percentage of damaged beans per plant within cage (\% Damage). Proportion of damaged beans did not vary with pollination treatment levels (Table $1, \mathrm{p}=0.09$ ). We tested all plant yield and growth variables, and used $\mathrm{P}+/ \mathrm{P}$ - treatment and $\%$ Damage per plant and their interaction term as explanatory variables. The random structure in all models included cage identity $(\mathrm{N}=28)$ nested within block $(\mathrm{N}=7)$, except for yield $\left(\mathrm{kg} \cdot \mathrm{ha}^{-1}\right)$ per cage where only block was included. If significant interactions were found, post-hoc tests using the "emmeans" package were carried out to investigate the direction of the effect.

To test the effects of herbivory on observed pollinator behaviour (proportion of legitimate, robbing and EFN visits) and on pollinator visitation rate (visits per flower per time unit) we used a generalized mixed-effects model with a binomial and a normal distribution respectively. The explanatory variables included $\mathrm{H}+/ \mathrm{H}-$ treatment and the number of open flowers per $\mathrm{m}^{2}$ and their interaction term. To account for addition of sugar-water to the pollinators on the $7^{\text {th }}$ of July a binary factor (sugar-water: yes/no) was included as well as its interaction with number of open flowers per $\mathrm{m}^{2}$ and herbivory treatment. The interaction between herbivory treatment and sugar-water was never significant and did not improve the models as determined by the Akaike Information Criterion (AIC), indicating that the effect of herbivory on pollinator behaviour did not change after the addition of the sugar-water. This interaction was therefore excluded. To investigate the effect of herbivores on number of open flowers per $\mathrm{m}^{2}$ in cages with pollinators, we used a generalized mixed-effects model with $\mathrm{H}+/ \mathrm{H}$ - treatment as explanatory variable. The random structure for all models incorporated the sampling round $(\mathrm{N}=15)$ nested within cage identity and block.

The residuals of all models were visually inspected to validate the model assumptions and additionally, generalized linear models were checked for overdispersion using "DHARMa" (Hartig \& Lohse, 2020). Multicollinearity was checked for all models (variation inflation factor $<2$ ). All analyses were conducted in $\mathrm{R}$ version 3.6.3, using packages "nlme" (Pinheiro \& Bates, 2020), "lme4" (Bates et al., 2020), "emmeans" (Lenth et al., 2021) and "ggplot2" (Wickham et al., 2020) to plot data.

\section{Results}




\section{Yield and its components}

Lack of pollination (P-) decreased total bean weight per plant, mean number of beans per pod and total number of beans per plant, independently of the herbivory treatment (Table 1, Fig. 1b,c, Fig. S4). In the absence of insect pollination, bean weight and number of beans per plant decreased by $15 \%$ and $17 \%$, respectively. There was a marginal $(p=0.06)$ interactive effect of pollination and herbivory on individual bean weight, with pollination increasing individual bean weight but only in the absence of herbivory (Table 1, Fig. 1a, Fig. S4). Herbivory increased percent damaged beans, with on average $39 \%$ damaged beans in the $\mathrm{H}+$ treatment (Table 1, Fig. S3), which is over tenfold the economic injury threshold set for beans targeting human consumption and could lead to up to $78 \%$ economical losses (Bachmann et al., 2020; Roubinet, 2016). There was no effect of pollination nor herbivory treatments on yield $\left(\mathrm{kg} \cdot \mathrm{ha}^{-1}\right)$, or mature or total number of pods per plant, however, proportion of mature pods was lower with lack of pollination, due to higher numbers of unfertilized and immature pods (Table 1, Fig. 1d, Fig. S4).

When herbivory damage on each plant was used as an explanatory variable (\% Damage), there were interactive effects of pollination and herbivory damage on individual bean weight, total bean weight per plant, and number of beans per pod (Table 1, Fig. 2, Fig. S5). In the absence of pollination, there were positive relationships between yield and herbivory damage for several yield components (individual bean weight: est $=0.001$, se $=0.0004, \mathrm{p}<0.01$; total bean weight: est $=0.06, \mathrm{se}=0.02, \mathrm{p}<0.01$; and number of beans per pod: $\mathrm{est}=0.007, \mathrm{se}=0.002, \mathrm{p}<0.01$ ) (Fig. 2, Fig. S5). In the presence of insect pollination, there were no relationships with herbivory damage. In addition, number of beans per plant increased with increasing herbivory damage independent of pollination treatment (Table 1). Number of pods per plant was not affected, but proportion of mature pods increased with herbivory damage due to a decrease in the number of unfertilized and immature pods (Table 1).

\section{Plant growth}

Plant above-ground biomass and height were higher with lack of pollination (Table 1, Fig. 1e, Fig. S4). While there was no effect of pollination or herbivory on root biomass, root length was marginally $(\mathrm{p}=0.06)$ shorter in the presence of herbivory (Table 1, Fig. 1f, Fig. S4), this effect became significant when using B. rufimanus \% Damage as an explanatory variable (Table 1, Fig. S5). In addition, there was a negative relationship between herbivory damage and plant above-ground biomass and height (Table 1, Fig. S5). 
a.
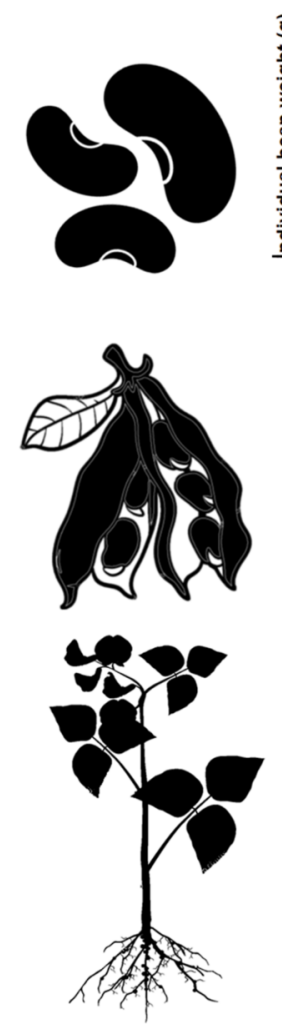

c.
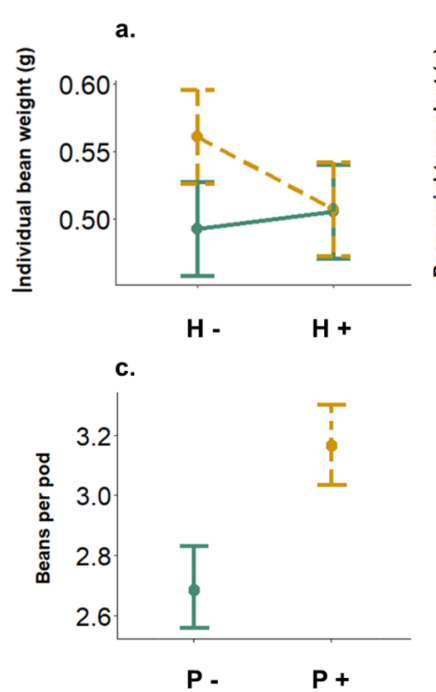

e.

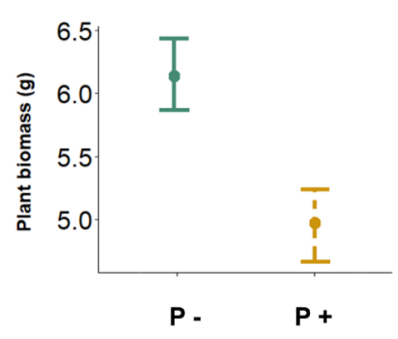

b.

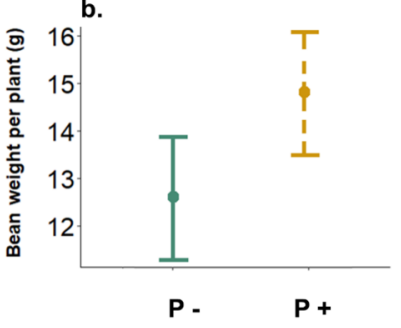

d.

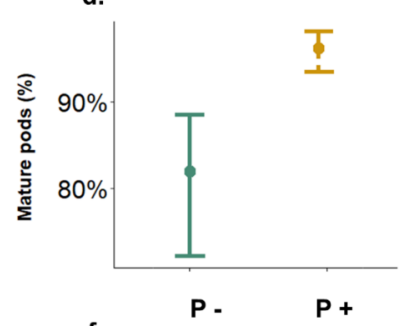

f.

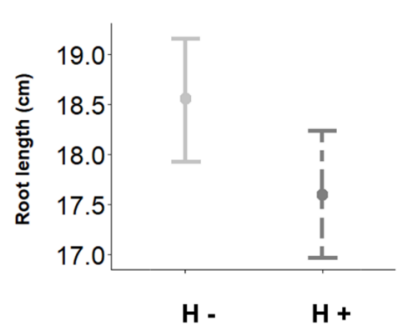

Fig. 1. Model prediction for faba bean yield and growth components in relation to herbivory (H- : solid light grey line ; and $\mathbf{H}+$ : dashed dark grey line ) and pollination ( $\mathbf{P}-$ : solid green line; and $\mathbf{P}+$ : dashed yellow line) levels: a. mean individual bean weight (g), b. bean weight per plant (g), c. number of beans per pod, d. percentage of mature pods per plant, e. aboveground plant dry biomass (g) and f. tap root length $(\mathrm{cm})$ per plant. Whiskers represent $95 \%$ confidence intervals. Note that y-axes do not start at 0 .
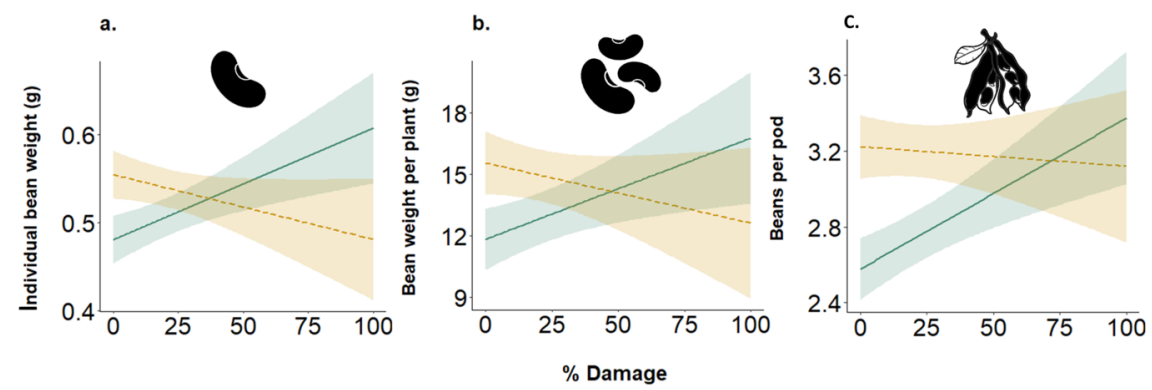

Fig. 2 . Model predictions for faba bean yield components in relation to herbivory damage (\% of beans with $B$. rufimanusemergence holes per plant) and pollination levels $(\mathbf{P}-$ : solid green line; and $\mathbf{P}+$ : dashed yellow line): a. individual bean weight (g), b. bean weight per plant (g) and (c) beans per pod. Bands represent $95 \%$ confidence intervals. Note that y-axes do not start at 0 .

Flower visitation 
Addition of sugar-water increased flower visitation rate (est $=0.36$, se $=0.11, \mathrm{p}=0.01$ ) and the proportion of legitimate visits (est $=10.4, \mathrm{se}=2.6, \mathrm{p}<0.01)$ as expected. Despite a low flower visitation rate (mean=0.03, $\mathrm{sd}=0.08, \min =0, \max =0.66$ visits per flower per $10 \mathrm{~min})$ and no effect of herbivory on visitation rate (est $=-0.05, \mathrm{se}=0.04, \mathrm{p}=0.31$ ), there was a negative effect of herbivory on proportion of legitimate flower visits by $B$. terrestris (mean $\pm \mathrm{se}=0.006 \pm 0.005 \%$, est $=-2.03$, $\mathrm{se}=0.89, \mathrm{p}=0.022, \mathrm{R}^{2}{ }_{\mathrm{m}}=0.05$ ), due to higher proportions of $\mathrm{EFN}$ visits (mean $\pm \mathrm{se}=84 \pm 4.3 \%$, est $=1.34$, $\mathrm{se}=0.53, \mathrm{p}=0.011, \mathrm{R}_{\mathrm{m}}{ }_{\mathrm{m}}=0.11$ ) but not robbing (mean $\pm \mathrm{se}=4.2 \pm 1.6 \%$, est $=-1.47, \mathrm{se}=0.81, \mathrm{p}=0.07$ ) (Fig. 3). While nectar robbing increased with the number of open flowers per $\mathrm{m}^{2}$ (est $=0.02$, $\mathrm{se}=0.01, \mathrm{p}=0.03$, Fig. S6), visitation rate and proportion of legitimate visitation were negatively affected by the number of open flowers per $\mathrm{m}^{2}$ but primarily after sugar-water was added (interaction term: visitation rate est $=-0.004, \mathrm{se}=0.002, \mathrm{p}=0.073, \mathrm{R}_{\mathrm{m}}{ }_{\mathrm{m}}=0.10$; proportion of legitimate visits est $=-0.09$, $\left.\mathrm{se}=0.04, \mathrm{p}=0.039, \mathrm{R}_{\mathrm{m}}{ }^{2}=0.42\right)$ (Fig. S6). However, there was no effect of herbivory on number of open flowers per $\mathrm{m}^{2}$ (est=- 4.69, $\mathrm{se}=5.55, \mathrm{p}=0.43, \mathrm{R}_{\mathrm{m}}{ }_{\mathrm{m}}=0.01$ ).
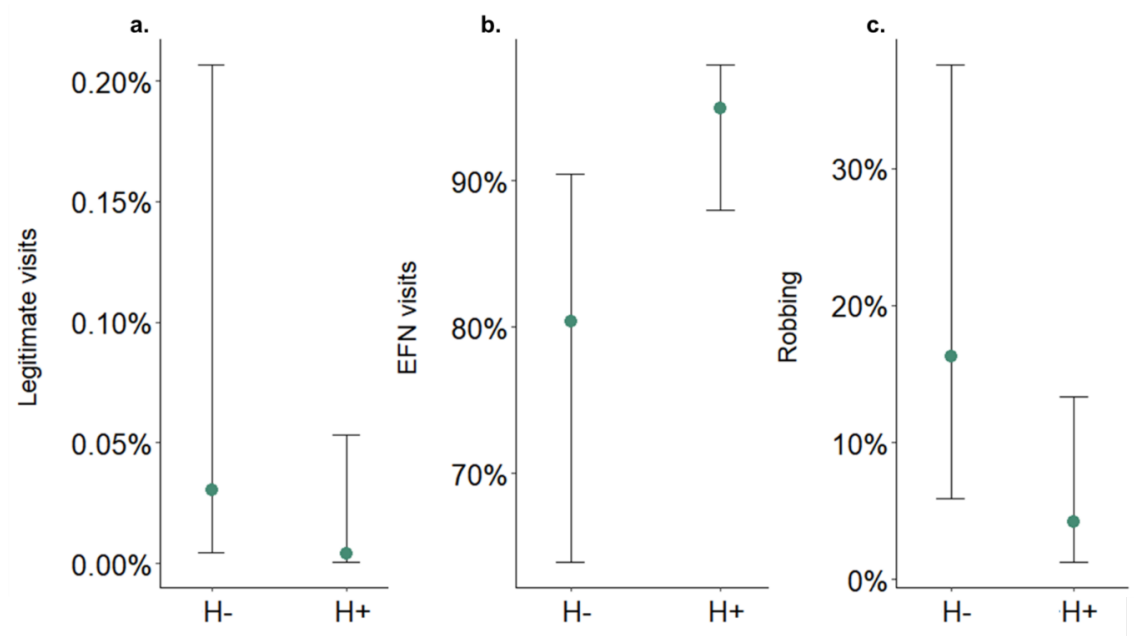

Fig. 3. Model prediction for percent of a. legitimate flower visits, b. EFN visits and c. robbing by $B$. terrestris in relation to a. herbivory $(\mathrm{H}-/ \mathrm{H}+)$ levels. Whiskers represent $95 \%$ confidence intervals. Note that $\mathrm{y}$-axis do not all start at 0 .

Table 1. Model outputs for both plant-stand (cage) and plant scale analyses. Presented are the yield and plant growth components with respect to pollination treatment $(\mathrm{P}+)$ and herbivory treatment $(\mathrm{H}+)$ or herbivory damage (\% of beans with B. rufimanus emergence holes per plant, \% Damage) and their two-way interactions. Shown are mean estimates (Est) for the respective treatments, standard errors (se), p-values (p) and the adjusted marginal $\mathrm{R}^{2}\left(\mathrm{R}_{\mathrm{m}}{ }^{2}\right)$ of the model. Significant results $(\mathrm{p}<0.05)$ are in bold . Plots for significant results and raw data are shown in Figs S4-S5.

\begin{tabular}{|c|c|c|c|c|c|c|c|}
\hline & Variables & $\mathbf{H}+$ & $\mathbf{P}+$ & $\mathbf{H}^{*} \mathbf{P}$ & $R_{m}^{2}$ & \%DamageP+ & \%Damag \\
\hline \multirow[t]{3}{*}{ Bean } & $\begin{array}{l}\text { ProportioEst } \pm \text { se } \\
\text { dam- } \\
\text { aged } \\
\text { beans }^{c}\end{array}$ & $3.85 \pm 0.64$ & 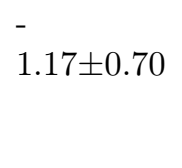 & $0.98 \pm 0.93$ & 0.59 & & \\
\hline & p & $\begin{array}{l}< \\
0.01\end{array}$ & 0.09 & 0.29 & & & \\
\hline & $\begin{array}{l}\text { IndividuaIEst } \pm \text { se } \\
\text { bean } \\
\text { weight } \\
(\mathrm{g})^{\mathrm{a}}\end{array}$ & $0.01 \pm 0.02$ & $0.06 \pm 0.02$ & $\overline{-}-0.06 \pm 0.03$ & 0.03 & $0.001 \pm 0.000407 \pm 0.01$ & 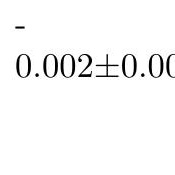 \\
\hline
\end{tabular}




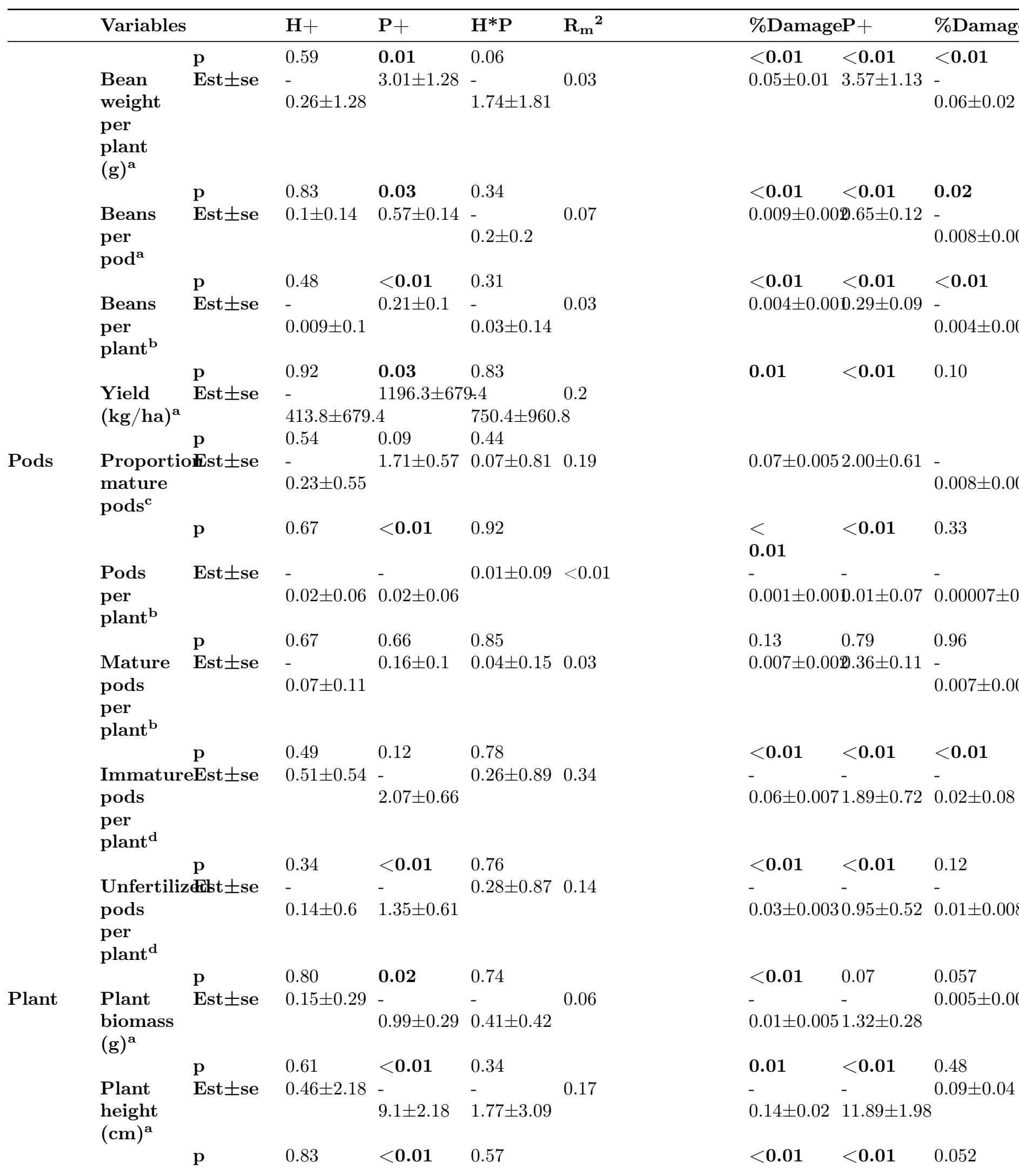




\begin{tabular}{|c|c|c|c|c|c|c|c|c|}
\hline \multicolumn{2}{|l|}{ Variables } & \multirow{3}{*}{$\begin{array}{l}\mathbf{H}+ \\
- \\
0.14 \pm 0.15\end{array}$} & \multirow{3}{*}{$\begin{array}{l}\mathbf{P}+ \\
- \\
0.20 \pm 0.15\end{array}$} & \multirow{3}{*}{$\begin{array}{l}\mathbf{H}^{*} \mathbf{P} \\
- \\
0.03 \pm 0.21\end{array}$} & \multirow{3}{*}{$\begin{array}{l}\mathbf{R}_{\mathbf{m}}{ }^{2} \\
0.01\end{array}$} & \multicolumn{2}{|c|}{ \%DamageP+ } & \multirow{2}{*}{ \%Damag } \\
\hline Root & Est \pm se & & & & & & - & \\
\hline $\begin{array}{l}\text { biomass } \\
(\mathrm{g})^{\mathrm{a}}\end{array}$ & & & & & & $0.003=$ & B). $21 \pm 0.14$ & $0.0004 \pm 0$. \\
\hline \multirow{4}{*}{$\begin{array}{l}\text { Root } \\
\text { length } \\
(\mathrm{cm})^{\mathrm{a}}\end{array}$} & $\mathrm{p}$ & 0.36 & 0.19 & 0.88 & & 0.29 & 0.14 & 0.92 \\
\hline & Est \pm se & - & $0.11 \pm 0.63$ & $0.61 \pm 0.91$ & 0.01 & - & $0.57 \pm 0.60$ & - \\
\hline & & $1.29 \pm 0.66$ & & & & $0.02 \pm$ & & $0.008 \pm 0.0$ \\
\hline & $\mathrm{p}$ & 0.06 & 0.85 & 0.51 & & 0.02 & 0.35 & 0.62 \\
\hline
\end{tabular}

a Linear mixed model with normal distribution ("Ime")

b Generalized linear mixed model (glmm) with a negative binomial distribution ("glmer.nb")

c Glmm with binomial distribution ("glmer")

d Glmm with Poisson distribution ("glmer")

\section{Discussion}

We asked how interactions between two hypothesized faba bean stressors - herbivory and lack of insect pollination - affect yield components (Fig. S1B). While lack of insect pollination is a clear stressor of faba bean, as it related negatively to several yield components, effects of herbivory by B. rufimanus were less straightforward.Bruchus rufimanus effects changed depending on the scale investigated: individual plant or plant-stand scale, when averaging individual plant scale responses at the cage scale. While no interactions between lack of insect pollination and herbivory were observed at the plant-stand scale (Fig. S1B), at the plant scale interactions were antagonistic, with increasing $B$. rufimanusdamage increasing yield components but only in the absence of pollinators. No negative effects of $B$. rufimanus on yield components were found at the plant-stand scale. Differences between the plant-stand and plant scale analyses in the effect on $B$. rufimanus are likely due to high variation in the level of herbivory damage among individual plants within cages (Fig. S3).

Despite high variation between faba bean cultivars in their dependency on pollinators (Bishop et al., 2020; Bishop \& Nakagawa, 2021), lack of insect pollination generally leads to lower yield in faba bean crops (Cunningham \& Le Feuvre, 2013; Free \& Williams, 1976; Raderschall et al., 2021; Riedel \& Wort, 1960; Suso et al., 1996; Suso \& del Río, 2015). This study confirms that lack of pollination decreases several faba bean yield components and is in line with a recent cage experiment using the same cultivar (Tiffany), where bean weight per plant and beans per pod but not individual bean weight benefitted from insect pollination (Raderschall et al., 2021). In the absence of pollinators, bean weight and number of beans per plant decreased by $15 \%$ and $17 \%$, respectively. Costs of lacking insect pollination were evident despite high frequencies of $B$. terrestris robbing, a common behaviour in this crop (Marzinzig et al., 2018), supporting the idea that robbing may benefit yield by increasing selfing in faba bean (Kendall \& Smith, 1975). Counterintuitively, visitation rate and proportion of legitimate flower visits decreased with number of open flowers (after sugar-water addition), while proportion of nectar robbing increased (Fig. S6). This is likely due to nectar deprivation at the start of the study, which meant that $B$. terrestris shifted from robbing nectar to legitimate visit later in the season when there were less flowers open. The low frequency of legitimate flower visits could, explain why the decrease in bean weight per plant due to lack of pollination (15\%) was modest when compared to results from a recent meta-analysis of faba bean pollinator dependency ( $37 \%$ on average, Bishop \& Nakagawa, 2021) or an experiment using the same cultivar (Tiffany) and bumblebee hives (61\%, Raderschall et al., 2021). In addition, a recent field study using the cultivar Tiffany, found no dependence on insect pollination (Lundin \& Raderschall, 2021), indicating high variation in pollination benefit within this cultivar, likely mediated by environmental conditions. Finally, despite observed yield benefits with B. terrestris in this experiment, field studies have found that less frequent and more specialised pollinator species with long tongues, such as $B$. 
hortorum, improve pollination and cross-fertilisation of faba bean compared to B. terrestris (Marzinzig et al., 2018). Further studies investigating pollination and herbivory interaction in faba bean should include a greater diversity of pollinator species varying in their behaviour.

The effect of the pest $B$. rufimanus on crop yield was inconclusive. While there was a higher proportion of damaged beans in the presence of $B$. rufimanus, which meant that the stand was non-marketable for human consumption due to aesthetic damage to the beans ( $>3 \%$ damage threshold, Bachmann et al., 2020; Roubinet, 2016) (Fig. S3b), this did not translate to a lower total or individual bean weight, number of beans or pods per plant. This is in contrast to bean aphid herbivory, which reduced all yield components (Raderschall et al., 2021). However, we found a marginal interaction $(\mathrm{p}=0.06)$ between pollination and $B$. rufimanus herbivory on individual bean weight, whereby individual bean weight was heavier with pollination, but only when B. rufimanus herbivory was absent. While we found no evidence that bumblebees legitimately visited flowers less frequently, proportion of legitimate flower visits decreased and EFN visits increased in the presence of $B$. rufimanus. Insect pollination has been shown to increase individual bean weight (Suso \& del Río, 2015), therefore, reduced proportion of legitimate flower visits due to B. rufimanus direct interference with pollinators or indirect damage caused by feeding on pollen, could lead to lower individual bean weight. There is, to our knowledge, no literature investigating damage to flowers or pollen by $B$. rufimanus adults. This interaction was, however, not apparent on other yield components, such as number of beans per pod and per plant. This might be because the number of beans is primarily determined by ovule fertilisation (pollination), while individual bean weight might also be affected by plant resource allocation after fertilisation, which could have been adversely impacted by the presence of B. rufimanus (Patrick \& Stoddard, 2010). Adverse herbivory effects of leaf chewers and sap feeders on bean weight have been found in Fabacea (Cuny et al., 2018; Raderschall et al., 2021). Therefore, resource allocation to developing beans might have been compromised by B. rufimanus and lead to lower individual bean weight when pollinators were present.

We detected a high variation in B. rufimanus damage between plants within cages (Fig. S3). When analysing the effect of $B$. rufimanus, at the individual plant scale we detected interactions and, generally, positive relationships between $B$. rufimanus herbivory damage and yield components, but only in the absence of pollination by $B$. terrestris. This indicates that the level of damage caused by $B$. rufimanus affects plant resource allocation, and that this response depends on the presence of pollinators. Two non-exclusive mechanisms, plant overcompensation and pollination by adult B. rufimanus, explaining these results are discussed below.

A biological process, which potentially underlies the differential response to herbivory depending on pollination treatment, is the capacity of faba bean plants to overcompensate for damage or stress (López-Bellido et al., 2005). Faba bean might overcompensate for early and high pod damage by B. rufimanus by increasing pod production or bean weight during their growth. This is because the growth of faba beans is indeterminate, and while pods are developing at the lower nodes, flower production continues at the upper ones. This leads to competition for resources within the plant between the first set of pods, the roots, bean growth, as well as with the developing pods further up the stem (Jaquiery \& Keller, 1978; Smith, 1982). Roots were on average $5 \%$ shorter in the presence of $B$. rufimanus and root length correlated negatively with herbivory damage. This indicates alterations in resource allocation from roots to other plant parts in the presence of $B$. rufimanus (Heinze, 2020). Further studies quantifying faba bean root nodules in interaction with herbivory and lack of pollination would shed some light on plant resource acquisition and allocation in relation to biotic stress. Plants might have overcompensated for herbivory damage in the absence of pollinators, as several yield components in highly damaged plants were higher compared to undamaged plants (Fig. 2). Overcompensation in terms of seed-set in response to herbivory is common in other crops such as Brassicaceae (Gagic et al., 2016; Rusman et al., 2018). Increase in yield components with increasing B. rufimanus damage were only visible in the absence of pollinators, when plants were stressed by both a lack of pollination and high herbivory damage. Plant resource allocation is complex, especially so in plants with indeterminate growth. We found that in the absence of pollinators, faba bean plants had a higher above-ground biomass, likely to compensate for insufficient fertilisation (Raderschall et al., 2021). Higher plant biomass might enhance photosynthetic capacity and result in higher ability to overcompensate to B. rufimanus damage in the ab- 
sence of pollination. However, very little is known about how plants optimize their resource allocation under multiple stressors.

Another non-exclusive biotic process that can explain the observed increases in yield with increasing herbivory in the absence of bumblebee pollination is that of pollination by B. rufimanus. Indeed, florivorous herbivores potentially act as pollinators if they transfer pollen between (cross-pollination) or within (self-pollination) plants. For example, damage by the bud-clipping weevil Anthonomus signatus lead to an increase in selfpollination in strawberries (Penet \& Collin, 2009). Faba bean plants that had greater level of herbivory damage might have had flowers that were visited more often by B. rufimanus, leading to positive associations between damage and pollination by $B$. rufimanus and increased yield components in highly damaged plants. The positive effects of $B$. rufimanus on yield were only visible in the absence of bumblebee pollination, an indication that when more efficient pollinators are present, B. rufimanus does not benefit faba bean pollination. While the net effect of bumblebees on yield components was positive, in the presence of both bumblebees and B. rufimanus, some plants likely received high numbers of visits and sustained more flower damage than what they could compensate for (Sáez et al., 2014), leading to lower bean weight per plant in the pollination treatment under high levels of herbivory damage. The fact that $B$. terrestris mainly robbed nectar instead of conducting legitimate visits could have influenced the results. Indeed we hypothesize that more legitimate visits would lead to higher rates of cross-pollination and higher yields in the presence of pollinators. In iris, a short-tongued bumblebee shifted to more nectar robbing and longer flower handling time during legitimate flower visits than long-tongued species because of increased competition with a florivorous sawfly (Ye et al., 2017). We did not find an effect of B. rufimanus on nectar robbing, but there was a negative effect on proportion of legitimate flower visits. . While nectar robbing is a common foraging behaviour in the field (Marzinzig et al., 2018), further studies also with long-tongued bumblebee species present, which mainly conduct legitimate visits, are necessary to understand interactions between florivory and pollination in faba bean.

Differences in B. rufimanus effects at different scales (plant-stand versus individual plant level) are likely due to differences between plants in the amount of florivory, oviposition and pollination visits they received. At the plant-stand scale, taking into account variation in B. rufimanus herbivory damage, pollinators have a positive effect while $B$. rufimanus only have a tendency to interact with pollinators and negatively affect individual bean weight. On the other hand, at the individual plant scale, herbivory damage by $B$. rufimanus strongly and positively correlates with yield components but only in the absence of pollinators. Effects of $B$. rufimanus on yield components were only visible when high levels of pest damage per plant $(>50 \%$, see Fig. $2 \mathrm{a}, \mathrm{b})$ were included in the analysis - damage levels, which are not occurring at plant-stand-level means in the cages, which are below $50 \%$ (Fig. S3b). In the field, B. rufimanus damage is, to our knowledge, generally lower than $50 \%$ and so interactions with pollinators might be less relevant for commercial production. In addition, the scenario of pollinators being absent, which is where B. rufimanus benefitted yield components, is not, yet, realistic in the field. Therefore, under field conditions, it is unlikely that B. rufimanus directly affects faba bean crop yield. However, the negative and indirect effects of $B$. rufimanus on individual bean weight and proportion of legitimate visits by pollinators call for further studies of these interactions in the field.

In summary, we confirm an insect pollination benefit on several faba bean yield components despite low rates of legitimate pollination, whereas plant responses to $B$. rufimanus herbivory differed on the individual versus plant-stand scale. Interestingly, positive effects of $B$. rufimanus herbivory were found on faba bean yield components, but only in the absence of pollinators and under high levels of herbivory damage. Another interesting result is that of a tendency for higher individual bean weight due to pollination, but only in the absence of $B$. rufimanus. Further studies at the plant scale level to understand how the plant allocates its resources under varying levels of pollination and herbivory would be required to clarify the mechanisms driving these interactions. In addition, to disentangle the effects of pollen limitation from other factors, such as flower damage due to high visitation rates, it will be important to investigate effects of herbivory in hand pollinated plants. This is the first experimental evidence of interactive effects of B. terrestris and B. rufimanus on faba bean plants. While our results strengthen the case for management of pollinators to 
maximize pollination benefits in faba bean, there is no evidence for direct yield losses, in terms of total bean weight and numbers, at infestation level of $B$. rufimanusthat typically occur in the field despite high bean damage levels. Bean damage by the larvae will decrease faba bean saleability and germination and thus requires control. However, findings of a negative and indirect association between B. rufimanus and individual bean weight and proportion of legitimate visits by pollinators call for an improved understanding of these interactions in the field.

\section{Acknowledgements}

We thank Robert Dinwiddie and Lina Norrlund at the Plant Protection Centers of the Swedish Board of Agriculture for their help and for sharing their data on Bruchus rufimanus surveys across Sweden. For technical assistance in the field and laboratory, we thank John Löfkvist, Ida Elisabeth Mackegård and Robyn Övergaard. We are grateful to Åsa Lankinen for reviewing the manuscript. Funding was provided by FORMAS, grant 2016-00626.

\section{Authors' contributions}

O.L. conceived the idea. L.R. conducted the experiment, analysed the data and wrote the manuscript. All co-authors planned the experiment and provided comments on the manuscript.

\section{Data availability statement}

Data will be made available via the free Swedish National Data Service (https://snd.gu.se/en).

\section{References}

Bachmann, M., Kuhnitzsch, C., Martens, S. D., Steinhofel, O., \& Zeyner, A. (2020). Control of bean seed beetle reproduction through cultivar selection and harvesting time. Agriculture, Ecosystems $\&$ Environment , 300, 107005. https://doi.org/10.1016/j.agee.2020.107005

Barrett, G. W., van Dyne, G. M., \& Odum, E. P. (1976). Stress Ecology.BioScience , 26 (3), 192-194. https://doi.org/10.2307/1297248

Bartomeus, I., Gagic, V., \& Bommarco, R. (2015). Pollinators, pests and soil properties interactively shape oilseed rape yield. Basic and Applied Ecology , 16 (8), 737-745. https://doi.org/10.1016/j.baae.2015.07.004

Bartomeus, I., Potts, S. G., Steffan-Dewenter, I., Vaissiere, B. E., Woyciechowski, M., Krewenka, K. M., Tscheulin, T., Roberts, S. P. M., Szentgyorgyi, H., Westphal, C., \& Bommarco, R. (2014). Contribution of insect pollinators to crop yield and quality varies with agricultural intensification. PeerJ , 2 (e328). https://doi.org/10.7717/peerj.328

Bates, D., Maechler, M., Bolker [aut, B., Walker, S., Christensen, R. H. B., Singmann, H., Dai, B., Scheipl, F., Grothendieck, G., Green, P., Fox, J., \& Bauer, A. (2020). lme4: Linear Mixed-Effects Models(1.1-26) [Computer software]. https://CRAN.R-project.org/package=lme4

Bishop, J., Garratt, M. P. D., \& Breeze, T. D. (2020). Yield benefits of additional pollination to faba bean vary with cultivar, scale, yield parameter and experimental method. Scientific Reports ,10 (1), 2102. https://doi.org/10.1038/s41598-020-58518-1

Bishop, J., \& Nakagawa, S. (2021). Quantifying crop pollinator dependence and its heterogeneity using multi-level meta-analysis. Journal of Applied Ecology , in press . https://doi.org/10.1111/1365-2664.13830

Cote, I. M., Darling, E. S., \& Brown, C. J. (2016). Interactions among ecosystem stressors and their importance in conservation.Proceedings of the Royal Society B-Biological Sciences ,283 (1824), 20152592. https://doi.org/10.1098/rspb.2015.2592

Cunningham, S. A., \& Le Feuvre, D. (2013). Significant yield benefits from honeybee pollination of faba bean (Vicia faba) assessed at field scale. Field Crops Research , 149 , 269-275. https://doi.org/10.1016/j.fcr.2013.05.019 
Cuny, M. A. C., Gendry, J., Hernandez-Cumplido, J., \& Benrey, B. (2018). Changes in plant growth and seed production in wild lima bean in response to herbivory are attenuated by parasitoids. Oecologia,187 (2), 447-457. https://doi.org/10.1007/s00442-018-4119-1

Epperlein, K. (1992). Investigation of the damage of broad bean weevil Bruchus rufimanus Bohem. (Col., Bruchidae) on broad bean seed (Vicia faba L.). Anzeiger fur Schaedlingskunde, Pflanzenschutz, Umweltschutz , 65 (8), 147-150.

Fisher, A., DeGrandi-Hoffman, G., Smith, B. H., Johnson, M., Kaftanoglu, O., Cogley, T., Fewell, J. H., \& Harrison, J. F. (2021). Colony field test reveals dramatically higher toxicity of a widelyused mito-toxic fungicide on honey bees (Apis mellifera). Environmental Pollution , 269 , 115964. https://doi.org/10.1016/j.envpol.2020.115964

Free, J. B., \& Williams, I. H. (1976). Pollination as a factor limiting the yield of field beans (Vicia faba L.). The Journal of Agricultural Science, 87 (2), 395-399. https://doi.org/10.1017/S0021859600027714

Gagic, V., Marcora, A., \& Howie, L. (2019). Additive and interactive effects of pollination and biological pest control on crop yield.Journal of Applied Ecology , 56 (11), 2528-2535. https://doi.org/10.1111/13652664.13482

Gagic, V., Riggi, L. G., Ekbom, B., Malsher, G., Rusch, A., \& Bommarco, R. (2016). Interactive effects of pests increase seed yield.Ecology and Evolution , 6 (7), 2149-2157. https://doi.org/10.1002/ece3.2003

Garcia, L. C., \& Eubanks, M. D. (2019). Overcompensation for insect herbivory: A review and meta-analysis of the evidence. Ecology ,100 (3), e02585. https://doi.org/10.1002/ecy.2585

Garibaldi, L. A., Andersson, G. K. S., Requier, F., Fijen, T. P. M., Hipolito, J., Kleijn, D., Perez-Mendez, N., \& Rollin, O. (2018). Complementarity and synergisms among ecosystem services supporting crop yield. Global Food Security , 17 , 38-47. https://doi.org/10.1016/j.gfs.2018.03.006

Hartig, F., \& Lohse, L. (2020). DHARMa: Residual Diagnostics for Hierarchical Regression Models (0.3.3.0) [Computer software]. https://CRAN.R-project.org/package=DHARMa

Heinze, J. (2020). Herbivory by aboveground insects impacts plant root morphological traits. Plant Ecology , 221 (8), 725-732. https://doi.org/10.1007/s11258-020-01045-w

Jaquiery, R., \& Keller, E. R. (1978). La chute des fruits chez la feverole (vicia faba l.) En relation avec la disponibilite en assimilats marques au 14c. Revue Suisse d'Agriculture , 10 (4), 123-127. 5893.

Jaremo, J., Tuomi, J., Nilsson, P., \& Lennartsson, T. (1999). Plant adaptations to herbivory: Mutualistic versus antagonistic coevolution.Oikos , 84 (2), 313-320. https://doi.org/10.2307/3546728

Jensen, E. S., Peoples, M. B., \& Hauggaard-Nielsen, H. (2010). Faba bean in cropping systems. Field Crops Research , 115 (3), 203-216. https://doi.org/10.1016/j.fcr.2009.10.008

Karkanis, A., Ntatsi, G., Lepse, L., Fernandez, J. A., Vagen, I. M., Rewald, B., Alsinga, I., Kronberga, A., Balliu, A., Olle, M., Bodner, G., Dubova, L., Rosa, E., \& Savvas, D. (2018). Faba Bean Cultivation Revealing Novel Managing Practices for More Sustainable and Competitive European Cropping Systems. Frontiers in Plant Science, 9 , 1115. https://doi.org/10.3389/fpls.2018.01115

Kendall, D. A., \& Smith, B. D. (1975). The Pollinating Efficiency of Honeybee and Bumblebee Visits to Field Bean Flowers (Vicia faba L.).Journal of Applied Ecology , 12 (3), 709-717. https://doi.org/10.2307/2402083

Krupnick, G. A., \& Weis, A. E. (1999). The Effect of Floral Herbivory on Male and Female Reproductive Success in Isomeris Arborea.Ecology , 80 (1), 135-149. https://doi.org/10.1890/00129658(1999)080[0135:TEOFHO]2.0.CO;2

Lenth, R. V., Buerkner, P., Herve, M., Love, J., Riebl, H., \& Singmann, H. (2021). Emmeans (1.5.5-1)

[Computer software]. https://CRAN.R-project.org/package=emmeans 
López-Bellido, F. J., López-Bellido, L., \& López-Bellido, R. J. (2005). Competition, growth and yield of faba bean (Vicia faba L.).European Journal of Agronomy , 23 (4), 359-378. https://doi.org/10.1016/j.eja.2005.02.002

Lundin, O., \& Raderschall, C. A. (2021). Landscape complexity benefits bumble bee visitation in faba bean (Vicia faba minor L.) but crop productivity is not pollinator-dependent. Agriculture, Ecosystems \& Environment , 314 , 107417. https://doi.org/10.1016/j.agee.2021.107417

Lundin, O., Smith, H. G., Rundlöf, M., \& Bommarco, R. (2013). When ecosystem services interact: Crop pollination benefits depend on the level of pest control. Proceedings of the Royal Society B: Biological Sciences , 280 (1753). https://doi.org/10.1098/rspb.2012.2243

Marzinzig, B., Brünjes, L., Biagioni, S., Behling, H., Link, W., \& Westphal, C. (2018). Bee pollinators of faba bean (Vicia faba L.) differ in their foraging behaviour and pollination efficiency.Agriculture, Ecosystems ES Environment, 264 , 24-33. https://doi.org/10.1016/j.agee.2018.05.003

McCall, A. C., \& Irwin, R. E. (2006). Florivory: The intersection of pollination and herbivory. Ecology Letters , 9 (12), 1351-1365. https://doi.org/10.1111/j.1461-0248.2006.00975.x

Munguía-Rosas, M. A., Arias, L. M., Jurado-Dzib, S. G., Mezeta-Cob, C. R., \& Parra-Tabla, V. (2015). Effects of herbivores and pollinators on fruit yield and survival in a cleistogamous herb. Plant Ecology,216 (4), 517-525.

Patrick, J. W., \& Stoddard, F. L. (2010). Physiology of flowering and grain filling in faba bean. Field Crops Research , 115 (3), 234-242. https://doi.org/10.1016/j.fcr.2009.06.005

Penet, L., \& Collin, C. L. (2009). Florivory increases selfing: An experimental study in the wild strawberry, Fragaria virginiana.Plant Biology , 11 (1), 38-45.

Peschiutta, M. L., Scholz, F. G., Goldstein, G., \& Bucci, S. J. (2020). Lagged effects of sawfly leaf herbivory on reproductive organs in cherry trees: Overcompensation in flower production reduces quality of fruits and seeds. Basic and Applied Ecology , 45 , 22-30. https://doi.org/10.1016/j.baae.2020.03.006

Peterson, R. K. D., \& Higley, L. G. (2000). Biotic Stress and Yield Loss . CRC Press.

Piggott, J. J., Townsend, C. R., \& Matthaei, C. D. (2015). Reconceptualizing synergism and antagonism among multiple stressors.Ecology and Evolution , 5 (7), 1538-1547. https://doi.org/10.1002/ece3.1465

Pinheiro, J., \& Bates, D. (2020). nlme: Linear and Nonlinear Mixed Effects Models (3.1-151) [Computer software]. https://CRAN.R-project.org/package $=$ nlme

Poveda, K., Díaz, M. F., \& Ramirez, A. (2018). Can overcompensation increase crop production? Ecology , 99 (2), 270-280. https://doi.org/10.1002/ecy.2088

Poveda, K., Jiménez, M. I. G., \& Kessler, A. (2010). The enemy as ally: Herbivore-induced increase in crop yield. Ecological Applications , 20 (7), 1787-1793. https://doi.org/10.1890/09-1726.1

Raderschall, C. A., Vico, G., Lundin, O., Taylor, A. R., \& Bommarco, R. (2021). Water stress and insect herbivory interactively reduce crop yield while the insect pollination benefit is conserved. Global Change Biology , 27 (1), 71-83. https://doi.org/10.1111/gcb.15386

Ramos, S. E., \& Schiestl, F. P. (2019). Rapid plant evolution driven by the interaction of pollination and herbivory. Science ,364 (6436), 193-196. https://doi.org/10.1126/science.aav6962

Riedel, I. B. M., \& Wort, D. A. (1960). The Pollination Requirement of the Field Bean (vicia Faba). Annals of Applied Biology ,48 (1), 121-124. https://doi.org/10.1111/j.1744-7348.1960.tb03510.x

Roubinet, E. (2016). Management of the broad bean weevil (Bruchus rufimanus Boh.) in faba bean (Vicia faba L.) [Report]. https://pub.epsilon.slu.se/13631/ 
Rusman, Q., Lucas-Barbosa, D., \& Poelman, E. H. (2018). Dealing with mutualists and antagonists: Specificity of plant-mediated interactions between herbivores and flower visitors, and consequences for plant fitness. Functional Ecology , 32 (4), 1022-1035. https://doi.org/10.1111/1365-2435.13035

Saez, A., Morales, C. L., Ramos, L. Y., \& Aizen, M. A. (2014). Extremely frequent bee visits increase pollen deposition but reduce drupelet set in raspberry. Journal of Applied Ecology ,51 (6), 1603-1612. https://doi.org/10.1111/1365-2664.12325

Sanchez, J. A., \& Lacasa, A. (2008). Impact of the Zoophytophagous Plant Bug Nesidiocoris tenuis (Heteroptera: Miridae) on Tomato Yield.Journal of Economic Entomology , 101 (6), 1864-1870. https://doi.org/10.1603/0022-0493-101.6.1864

Saunders, M. E., Peisley, R. K., Rader, R., \& Luck, G. W. (2016). Pollinators, pests, and predators: Recognizing ecological trade-offs in agroecosystems. Ambio , 45 (1), 4-14. https://doi.org/10.1007/s13280015-0696-y

Segers, A., Caparros Megido, R., Lognay, G., \& Francis, F. (2021). Overview of Bruchus rufimanus Boheman 1833 (Coleoptera: Chrysomelidae): Biology, chemical ecology and semiochemical opportunities in integrated pest management programs. Crop Protection , 140 , 105411. https://doi.org/10.1016/j.cropro.2020.105411

Smith, M. (1982). Factors affecting flower abscission in field beans (Vicia Faba L. Minor) [Doctoral, Durham University]. http://etheses.dur.ac.uk/7698/

Suso, M. J., \& del Rio, R. (2015). A crop-pollinator inter-play approach to assessing seed production patterns in faba bean under two pollination environments. Euphytica , 201 (2), 231-251. https://doi.org/10.1007/s10681-014-1200-7

Suso, M. J., \& Maalouf, F. (2010). Direct and correlated responses to upward and downward selection for outcrossing in Vicia faba. Field Crops Research , 116 (1), 116-126. https://doi.org/10.1016/j.fcr.2009.12.001

Suso, M. J., Moreno, M. T., Mondragao-Rodrigues, F., \& Cubero, J. I. (1996). Reproductive biology of Vicia faba: Role of pollination conditions. Field Crops Research , 46 (1), 81-91. https://doi.org/10.1016/03784290(95)00089-5

Sutter, L., \& Albrecht, M. (2016). Synergistic interactions of ecosystem services: Florivorous pest control boosts crop yield increase through insect pollination. Proceedings of the Royal Society B-Biological Sciences , 283 (1824), 20152529. https://doi.org/10.1098/rspb.2015.2529

Tamburini, G., Bommarco, R., Kleijn, D., Putten, W. H. van der, \& Marini, L. (2019). Pollination contribution to crop yield is often context-dependent: A review of experimental evidence. Agriculture, Ecosystems and Environment , 280 , 16-23. https://doi.org/10.1016/j.agee.2019.04.022

Tasei, J. N. (1976). Les insectes pollinisateurs de la feverole d'hiver (Vicia faba equina 1.) Et la pollinisation des plantes male-sterile en production de semence hybride. Apidologie , 7 (1), 1-28. https://doi.org/10.1051/apido:19760101

Vinebrooke, R. D., Cottingham, K. L., Norberg, J., Scheffer, M., Dodson, S. I., Maberly, S. C., \& Sommer, U. (2004). Impacts of multiple stressors on biodiversity and ecosystem functioning: The role of species co-tolerance. Oikos , 104 (3), 451-457.

Wickham, H., Chang, W., Henry, L., Pedersen, T. L., Takahashi, K., Wilke, C., Woo, K., Yutani, H., \& Dunnington, D. (2020). Ggplot2 (3.3.3) [Computer software]. https://CRAN.R-project.org/package=ggplot2

Ye, Z.-M., Jin, X.-F., Wang, Q.-F., Yang, C.-F., \& Inouye, D. W. (2017). Pollinators shift to nectar robbers when florivory occurs, with effects on reproductive success in Iris bulleyana (Iridaceae).Plant Biology , 19 (5), 760-766. https://doi.org/10.1111/plb.12581 